\title{
Encontro do parasita Hemencyrtus herbertii (Hymenoptera: Encyrtidae) em Musca domestica (Diptera: Muscidae) no Brasil Finding of Hemencyrtus herbertii
} (Hymenoptera: Encyrtidae) parasite breeding in Musca domestica (Diptera: Muscidae) in Brazil

\author{
Carlos H Marchiori, Luiz A Pereira e Otacilio MS Filho \\ Departamento de Ciências Naturais do Instituto Luterano de Ensino Superior de Itumbiara. Goiás, \\ GO, Brasil
}

\section{Descritores}

Moscas domésticas, parasitologia.

Hemencyrtus herbertii. Musca

domestica

Keywords

Houseflies, parasitology. Hemencyrtus

herbertii. Musca domestica.

\author{
Resumo \\ Relata-se a primeira ocorrência de Hemencyrtus herbertii parasitando pupas de $\mathrm{Musca}$ \\ domestica em fezes humanas no Brasil.
}

\begin{abstract}
This is the first report of the occurrence of Hemencyrtus herbertii (Hymenoptera: Encyrtidae) parasitizing pupae of Musca domestica (Diptera: Muscidae) in human feces in Brazil.
\end{abstract}

Os dípteros muscóides das famílias Calliphoridae, Fanniidae, Muscidae e Sarcophagidae são potenciais vetores mecânicos de agentes etiológicos como: vírus, bactérias, cistos de protozoários e ovos de helmintos. ${ }^{5}$ Esses dípteros são de grande interesse médico-sanitário e sua ocorrência, distribuição e predominância nas áreas metropolitanas são fatores de grande importância em saúde pública. ${ }^{5}$ As principais espécies, com referência à transmissão de patógenos, são as moscas sinantrópicas que se adaptaram às condições ambientais modificadas pelo homem. ${ }^{1}$ Musca domestica L. (Diptera: Muscidae) é a espécie de maior interesse sanitário devido a seu caráter sinantrópico, sua endofilia, abundância na região urbana, capacidade de se desenvolver em vários tipos de substratos, alto poder reprodutivo e ser apontada como veiculadora de patógenos ao homem e a animais. ${ }^{6-8}$

Juntamente com as moscas, desenvolvem-se uma variada fauna de predadores e parasitóides respon- sáveis pelo controle natural desses dípteros. Entre os principais inimigos das moscas, estão os parasitóides das famílias Chalcididae, Pteromalidae, Encyrtidae e Eucoilidae. ${ }^{4}$

O objetivo da presente nota é relatar a primeira ocorrência do parasitóide Hemencyrtus herbertii como inimigo natural de Musca domestica no Brasil.

O estudo foi realizado na Faculdade de Agronomia localizada no município de Itumbiara, GO $\left(18^{\circ} 25^{\prime} \mathrm{S}-\right.$ $\left.49^{\circ} 13^{\prime} \mathrm{W}\right)$. Procedeu-se à coleta de adultos de moscas por meio de armadilhas construídas com lata de coloração preta fosca, medindo cerca de $19 \mathrm{~cm}$ de altura por $9 \mathrm{~cm}$ de diâmetro, com duas aberturas tipo venezianas, localizadas no terço inferior, para permitir a entrada dos insetos. Na parte superior das latas, foram acoplados funis de nylon, abertos nas extremidades, com bases voltadas para baixo e envolvidos em sacos plásticos, cuja remoção permitiria a coleta das moscas. Serviram como iscas, para atração das moscas, 
rins de fígado bovino, fezes humanas, vísceras de frango e frutos depositados no interior das latas sobre uma camada de terra. Utilizaram-se cinco armadilhas que foram penduradas em árvores de eucalipto (Eucalyptus sp.) a um metro do solo, a dois metros uma das outras e a $50 \mathrm{~m}$ do lixo doméstico. Os indivíduos coletados foram levados para o laboratório, sacrificados com éter etílico e conservados em álcool $70 \%$ para posterior identificação.

Para a obtenção dos parasitóides, o conteúdo das armadilhas foi colocado em recipientes plásticos contendo uma camada de areia para servir de substrato à pupação das larvas. Peneirada essa areia (após 15 dias de sua colocação no campo), dela se extraíram as pupas, posteriormente colocadas individualmente em cápsulas de gelatina (número 00) para obtenção de moscas e/ou parasitóides. A prevalência de parasitismo foi calculada pelo número de pupas parasitadas/número total de pupas coletadas x 100 .

Após quatro coletas realizadas no período de maio a junho de 2001, obteve-se um total de 115 pupas, sendo 13 pupas de Musca domestica L. (Diptera: Muscidae) coletadas em fezes humanas, das quais cinco emergiram adultos, sete não emergiram nem adultos e nem parasitóides, provavelmente por mortalidade natural do hospedeiro, e de uma pupa emergiram cinco parasitóides gregários pertencentes à espécie Hemencyrtus herbertii Ashmead (Hymenoptera: Encyrtidae). Muitos gêneros de Encyrtidae apresentam reprodução poliembriônica, isto é, com muitos parasitóides emergindo de um único hospedeiro. ${ }^{2}$ Várias espécies dessa família têm sido utilizadas com sucesso em programas de controle biológico. Hemencyrtus herbertii comporta-se como parasitóide de larvas, desenvolvendo-se internamente no corpo do hospedeiro e emergindo do pupário. ${ }^{2} \mathrm{~A}$ prevalência total de parasitismo foi de $11,3 \%$, e, em pupas de $M$. domestica, de $38,4 \%$.

Hemencyrtus sp. foi coletado nos seguintes hospedeiros: Chrysomya albiceps, Hemilucilia flavifacies (Calliphoridae), Synthesiomyia nudiseta (Muscidae), Euboettcheria collusor, Oxysarcodexia sp. e Patonella intermutans (Sarcophagidae). ${ }^{3,9}$

Considerando-se a importância que esse inseto assume em saúde pública, como vetora de agentes causadores de doença, é essencial realizar o levantamento dessas espécies de inimigos naturais para auxiliar o controle adequado das moscas por meio de métodos integrados.

\section{REFERÊNCIAS}

1. D'Almeida JM, Almeida JR. Longevidade e curva de sobrevivência de oito espécies de dípteros caliptrados (Calliphoridae, Muscidae e Sarcophagidae), em condições de laboratório. Rev Bras Biol 1996;56:497-505.

2. Gauld ID, Bolton B. The Hymenoptera. New York: Oxford University; 1988.

3. Marchiori $\mathrm{CH}$. Parasitóides de estágios imaturos de dípteros sinantrópicos coletados em vários ambientais em Itumbiara-GO. Acta Sci 2000;22:655-61.

4. Marchiori $\mathrm{CH}$, Castro MEV, Paiva TCG, Teixeira FF, Silva CG. Dípteros muscóides de importância médica e veterinária e seus parasitóides em Goiás. Arq Bras Med Vet Zootec 2000;52:350-3.

5. Mariconi FAM, Guimarães JH, Filho EB. A mosca doméstica. Piracicaba: FEALQ; 1999.

6. Mendes J, Linhares AX. Atratividade por iscas, sazonalidade e desenvolvimento ovariano em várias espécies de Muscidae (Diptera). Rev Bras Ent 1993;37:289-97.

7. Nakano O, Leite CA. Armadilhas para insetos. Piracicaba: FEALQ; 2000.

8. Neves DP. Parasitologia humana. São Paulo: Editora Atheneu; 2000.

9. Silva AR. Himenópteros parasitóides associados a dípteros saprófagos, com especial referência aos Alysiinae (Braconidae) [Dissertação de Mestrado]. São Carlos: Departamento de Ecologia e Biologia Evolutiva da Universidade Federal de São Carlos; 1991. 